\title{
HEALTH POLICY AND MATERNAL MORTALITY IN RWANDA: A CASE OF RWAMAGANA DISTRICT HOSPITAL
}

\author{
Mr. HABARUREMA Samuel Gad ${ }^{1 *}$, Dr. Prudence NGARAMBE, PhD $^{2}$, Dr. Ernest SAFARI, PhD ${ }^{3}$, \\ ${ }^{* 1}$ Email: gadbarinda@gmail.com, ${ }^{2}$ Email: prudencengarambe3@gmail.com, \\ ${ }^{3}$ Email: safariernest2010@gmail.com
}

*Corresponding Author: -
Email: gadbarinda@gmail.com,

\begin{abstract}
The purpose of the study was to investigate the impact of health policy on maternal mortality in Rwanda, Rwamagana Hospital. The objectives of the study were: to investigate the impact of health policy on maternal mortality in Rwanda specifically Rwamagana Hospital, to examine the effect of medical insurance on maternal mortality rates in Rwanda Rwamagana Hospital, to find out the influence of training of medical staff on the maternal mortality rate in Rwanda Rwamagana Hospital, to find out the influence of mass immunization on maternal mortality rates in Rwanda especially in Rwamagana Hospital. The literatures were reviewed from different scholars and academicians in relation to the research study and the conceptual framework was based on three variables including independent variable shown as health policy and it was measured in terms of medical insurance, training medical personnel, and mass immunization, another variable was dependent variable shown as maternal mortality and it was measured in terms of malnutrition, disease, poor health services and poor antenatal care and another variable was the intervening variables that can falsify the findings of the study which includes building medical facilities, provision of medical care, educating women especially on human reproduction matters and hygiene and sanitation as well. The target population comprised 120 people and sample size of 92 respondents was considered using Yamane formula and purposive sampling technique was used. Questionnaires, documentary data and data analysis were expected to be used through SSPS version 21.0 while coding and cleaning the data collected from the field. The findings indicated that health policy has impact on maternal mortality in all health sectors of Rwamagana Hospital; for instance the results have indicated that health insurance is owned at rate of 91 (98.9\%), easy access to medication at rate of 6 (6.5\%), financial risk protection through protecting the resources spent on nursing sick children and maternal deaths at rate of 11 (12.0\%), building of medical infrastructures and facilities at rate of 61 (66.3\%). The findings also indicated there is correlation between health policy measure and maternal mortality prove that all the variables are positively significant at p-value under 0.05 , despite that all the variables in correlation with poor antennal care gave negative Pearson correlation implied that the betterment of health policy decreases maternal mortality and recommendations were drawn basing on the study findings and challenges faced by Health policy beneficiaries whereby recommendations were addressed to medical personnel, government of Rwanda mainly ministry of health, local leaders, and expectant mothers and hence suggestions for further studies in line with Health policy were advised by the researcher as the study got its progress.
\end{abstract}

Key Words: Health policy, Maternal Mortality, Medical insurance/ Health insurance, medical facilities, Immunization

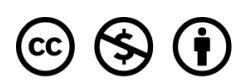




\section{INTRODUCTION}

The study was conducted to find out the impact of health policy on maternal mortality rate in Rwanda, Rwamagana Hospital. And the following was the background of the study based on reviewing others literature on health policy and maternal mortality. WHO (2016) refers health policy refers to decisions, plans, and actions that are undertaken to achieve specific health care goals within a society. An explicit health policy can achieve several things: it defines a vision for the future which in turn helps to establish targets and points of reference for the short and medium term. It outlines priorities and the expected roles of different groups; and it builds consensus and informs people. The maternal mortality rates (MMR) is the annual number of maternal deaths per 100000 live births, mainly caused by bad Management of pregnancy or for other reasons in connection with or through pregnancy (with the exception of) unintended and coincidental reasons) tightened up. The MMR includes deaths during pregnancy, birth, or within 42 days of termination of pregnancy, irrespective of the duration and location of the pregnancy for a specified year ( $\mathrm{MOH}, 2017)$.

The greatest decline over that period was observed in Eastern Asia (72\%). As of 2015, the two regions with highest MMR are sub-Saharan Africa (546; UI 511 to 652) and Oceania (187; UI 95 to 381). Trends in the estimates of the maternal mortality ratio (motherly death per one hundred thousand live births) and progress in the direction of MDG5A, after global maternal mortality trend estimated since 1990-2015, accomplished this goal MDG Rwanda 5A (WHO-2015:10). The Health sector in Rwanda has made significant progress in recent years (Binagwaho et al., 2011). Reproductive Health, including Family Planning and Maternal health is a priority in Ministry of Health Strategic Plan and the fight against maternal death is a concern in Rwanda and is registered among MDGs priorities (MOH, 2014). Improved surveillance and accountability have played a large role in reducing the MMR and increasing the number of assisted deliveries in Rwanda. The Maternal Mortality rate in Rwanda drop from 750 (DHS: 2005) to 540 in year 2008 and to 383 according to Health Management Information System (HMIS: 2010). However, there is still persistence of maternal mortality in Rwanda despite the much effort applied by health policy of Rwanda. Hence, the reason the researcher finds out the impact of health policy on maternal mortality rate in Rwamagana Hospital, Rwanda.

\section{Statement of the Problem}

An estimated 287,000 maternal deaths occurred worldwide in 2010, many of them were born in less and developing countries where are located people with low and middle incomes and were avoidable (UN, 2010). Though the whole world has drafted and implemented many counter maternal mortality programs and policies. Maternal mortality rate is still high in Rwamagana Hospital with a rate of 210 MMR per 100, 000 live births (Rwanda EPCMD, 2017). The Maternal Mortality Rate has fallen in recent years, but still high (Basinga, 2011). Despite all the measures and health policies adopted by ministry of health in Rwanda, it is in this regard the researcher ambitiously looked forward to find out the impact of health policy on maternal mortality in Rwamagana Hospital - Rwanda which remains high, though the government of Rwanda has put so much effort in counter maternal mortality related health policy and measures.

\section{Objectives of the study}

\subsection{General Objective}

To assess the impact of health policy on maternal mortality rate in Rwamagana Hospital, Rwanda.

\subsubsection{Specific Objectives}

(i) To examine the effect of community based health insurance on maternal mortality in Rwamagana Hospital, Rwanda;

(ii) To investigate the impact of training medical personnel on maternal mortality rate in Rwamagana Hospital, Rwanda;

(iii) To assess the impact of mass immunization on maternal mortality rate in Rwanda specifically in Rwamagana Hospital.

(iv) To find out correlation between health policy and maternal mortality in Rwamagana Hospital, Rwanda.

\section{Literature Review}

\subsection{Empirical Review}

Numerous studies were conducted in this field of health policy and maternal mortality rate. To analyze the implication of health policy that is applied to ensure reduction of maternal mortality rate. The study conducted by Lewis (2001) in London, analyzed why mothers die, this study find that maternal mortality is not only in less developed countries rather even in developed countries. Until September 2012 the UHC built on CBHI had been observed nowhere in the world; the model of Rwanda UHC would be therefore the first of the kind. Carrin et al,. (2008) started that the transition to Universal Health Coverage starts from stage 1 where there is no financial protection to stage 3 where universal coverage is effective. Considering different stages of transition to UHC as proposed by Carrin (2016) the results of the study will be used to range Rwanda UHC. Five basic factors highlight the Rwanda commitment to move towards UHC: The long-term strategy Vision 2020 with a strategic social protection through universal access to health care (2000), The Rwanda's Politique Nationale de Développement des Mutuelles (2004); The Law No 62/2007 of December 30th promulgated in March 2008 which states that all Rwandan residents must be affiliated to a health insurance scheme that provides quality health care; The Rwanda Community Based Health Insurance Policy 2010; The Rwanda National Health Insurance Policy 2010. Global evidence suggests that health insurance increase health service access and utilization. Owoo (2013) found that women who sign up to health insurance were more likely to use antenatal services compared with women who do not. He added that they are also more likely to have fewer birth complications and experience fewer infant deaths. Brugiavini and Pace (2015) also found that NHIS membership positively affects the probability of institutional delivery and assistance by skilled personnel during delivery. Health insurance has also been linked to improved maternal, newborn and child 
health outcomes. Governments may also offer health insurance often financed through general tax revenue and targeted at specific populations, henceforth referred to as 'public health insurance'. Particularly in Latin America and Asia, governments may offer public health insurance schemes for low-income individuals (Laurel, 2013).Such health insurance policies are typically affordable only by wealthier groups in low- and middle-income countries (Laurel, 2013).

A number of studies also provided evidence from CBHI schemes. For example, in Rwanda, CBHI members were 1.6 times more likely to deliver in a modern health facility compared to uninsured women (Mugeni, 2011). Another study from Rwanda's CBHI scheme found that insured women are three times more likely to deliver with professional assistance compared to uninsured women who are more likely to deliver at home alone (Sekabaraga et al., 2011). Thus, this shows that the number of insured women might be significantly reduced when it goes to maternal mortality and infant mortality. This also show that health policy application determines the maternal life of the women in the govern area. Elsewhere, in Mali and Senegal where other empirical studies were conducted showed that there is significant variation in terms of baseline estimates; the rates of facility-based deliveries are $65 \%$ and $71 \%$ respectively compared to $27 \%$ in Rwanda for baseline outcomes and effect-sizes (Rich, 2012). This study also shows that Rwanda - Mutual health insurance which is CBHI is voluntary enrolled by $91 \%$ of the population to own health insurance and reached $85 \%$ of the target population (Sekabaraga, 2011). Paf et al,. (2016) argues that owning mutual health insurance in Rwanda has also led to a reduction in health-care costs, and the increased use of health-care services. Taken together with other reforms such as the decentralization of health-care services, performance-based financing, quality insurance and improvements in quality control through supervision, Paf et al,. (2016) believes mutual health insurance ownership has made a significant contribution to the well-being of the population.

\subsection{Conceptual framework}

Mile \& Huberman (1994) defined a conceptual framework as a visual or written product that explains, either graphically or in narrative form, the main things to be studied such as key factors, concepts or variable and presumed relationships among them. Thus, in this study, the conceptual framework is based on three variables including independent variable shown as health policy which is measured in terms of medical insurance, training medical personnel, and mass immunization, another variable was dependent variable shown as maternal mortality and it is measured in terms of malnutrition, disease, poor health services and poor antenatal care and lastly the intervening variables that can falsify the findings of the study which includes building medical facilities (clinics, dispensaries, pharmacies and hospitals), provision of medical care, education women especially on human reproduction matters, and hygiene and sanitation. As show in the below figure 2.1

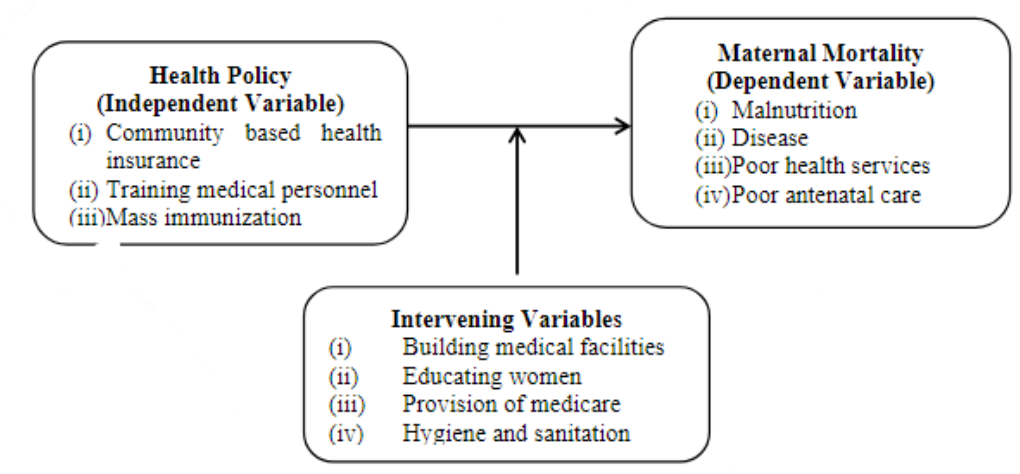

Source: Researcher, 2017

Figure 2.1: Conceptual framework

The figure 2.1 shows the independent variables as health policy and dependent variables as maternal mortality. It further shows that health policy was measured in terms of medical insurance, training medical personnel, and mass immunization while maternal mortality was measured in terms of malnutrition, disease, poor health services and poor antenatal care. The figure also reveals that apart from health policy, other factors such as building medical facilities (clinics, dispensaries, pharmacies and hospitals), provision of medical care, education women especially on human reproduction matters and hygiene and sanitation may also affect maternal mortality rate in Rwamagana Hospital - Rwanda.

\section{Research Methodology}

This study adopted descriptive research design to facilitated the process of data collection that involve both qualitative and quantitative data that show a clear picture of the situation of health policy and maternal mortality in Rwamagana Hospital, Rwanda. This mixed approach of qualitative and quantitative data which is preferred because they build a broader picture by adding depth and insights to numbers through inclusion of dialogue and narratives that facilitate to capture diverse perspectives, facilitate planned minimum statistical analysis to enable quantitative summary of findings to add breath to the study and work towards making it more representative (Gay, 1987). This study portrayed accurately the characteristics of the situation in other District Hospitals in Rwanda in terms of structures, medical insurances, medical personnel trainings and immunization system, hence criteria bias was reduced and reliability of evidence to be collected was maximized because Amin (2005) supports use of case studies especially where the area has been not studied before. In this case, health policy and maternal mortality has not studied which mean to study it is appropriate. 
This study involves 120 people in the hospital of Rwanda including 78 staffs and 42 maternal ward attendees. The sample of 92 respondents is drawn from 120 people using Yamane (1967) formula. As represented in the below table 3.1

Table 3.1. Sample size of respondents

\begin{tabular}{llll}
\hline Number of Respondents & Population & Sample & Sampling Technique \\
\hline Hospital staff & 78 & 60 & Simple random \\
Maternity ward attendees & 42 & 32 & Simple random \\
Total & $\mathbf{1 2 0}$ & $\mathbf{9 2}$ & Use of Yamane (1967) \\
\hline
\end{tabular}

Source: Researcher, 2017

The simple random sampling is used to select 92 respondents from the 120 target population. Hence, the rational to use simple random sampling is because all the respondents of this study have equal chances in being selected to contribute in this study.

The researcher used questionnaire and interview guide to collect information from the respondents of the study. The questionnaires were given to all respondents who were able to read and write who are 88 respondents and only 4 respondents were given interviews. The secondary data was collected from text books, national documentaries, journals, internet and annual reports. The data to be collected included both qualitative and quantitative. In this study, the primary data was collected using Questionnaire, interview guide and accumulated a comprehensive report on the impact of health policy on maternal mortality which was administered in three stages (before, during and after) administration.

\section{Research key findings}

\subsection{Effect of Community Based Health Insurance on Maternal Mortality}

In this section, the researcher presented, analyzed and interpreted the respondents' perceptions in relation to the impact of community-based health insurance on maternal mortality rate in Rwamagana District Hospital.

Table 5.1: Descriptive statistics on having health insurance before and after Health Policy implementation

\begin{tabular}{|c|c|c|c|c|}
\hline & Before CBHI & & After CBHI & \\
\hline$\underline{\text { Health insurance }}$ & Frequency & Percentage & Frequency & Percentage \\
\hline Yes & 60 & 65.2 & 91 & 98.9 \\
\hline No & 32 & 34.8 & 1 & 1.1 \\
\hline Total & 92 & 100.0 & 92 & 100 \\
\hline
\end{tabular}

Source: Primary Data, 2018

The results in Table 4.1 show that before joining Community Based Health Insurance only $60(65.2 \%)$ had health insurance, while $32(34.8 \%)$ did not have health insurance. However, after joining community-based health insurance the number of the people who had health insurance has increased whereby 91 (98.9) of respondents had health insurance whereas only $1(1.1 \%)$ of the respondents did not have health insurance. Thus, implies that the community-based health insurance has influenced ownership of health insurance. Basing on the findings of Mugeni (2011) proving that communitybased health insurance owners tend to give birth in hospitals with improved health care. The results of this study affirm that community-based health insurance has great impact on reducing maternal mortality in Rwamgana Hospital, Rwanda. In an interview with Community Based Health Insurance confirmed that the number of health insurance has significantly increased among the local people after the government's health policy that have specifically focused on the communitybased health insurance. He stated in his word that "Since the amendment of health policy in 2013, the hospital has experienced a big number of people who come for immunization, vaccination and other health services due to much much sensitizations, awareness, mobilization in order to ensure the wellbeing of the people through alleviation of maternal mortality, diseases, fatal death and financial risk protection to mention but few.

Table 5.2: descriptive Statistics on improvement done by CBHI policy

\begin{tabular}{lll}
$\begin{array}{l}\text { Other Improvement done by CBHI } \\
\text { beneficiaries }\end{array}$ & Frequency & Percentage \\
\hline $\begin{array}{l}\text { Hospital deliveries } \\
\text { Easy access to medication }\end{array}$ & 4 & 4.3 \\
Quality health services & 6 & 6.5 \\
Financial risk protection & 5 & 5.4 \\
Nutritional awareness & 11 & 12.0 \\
Two of the above listed & 1 & 1.1 \\
Three of the above listed & 10 & 10.9 \\
four of the above listed & 21 & 22.8 \\
All of the above listed & 18 & 19.6 \\
Total & 16 & 17.4 \\
\hline
\end{tabular}

Source: Primary Data, 2018 
The findings in Table 4.2 show that 21 (22.8\%) of respondents have benefited from three of the improvement brought by community based health insurance, $18(19.6 \%)$ of respondents have confirmed that they benefited from four improvement made by community based health insurance, $16(17.4 \%)$ admits to have benefited from four improvements made by CBHI and $10(10.9 \%)$ have also benefited from two improvements made by CBHI, whereas financial risk protection, easy access to medication, quality health services, hospital deliveries and nutritional awareness have also been improved through ownership of CBHI at the ranking of 11 (12.0\%), 6 (6.5\%), 5 (5.4\%), 4 (4.3\%), 1 (1.1\%) respectively. Thus, it implies that the improvements brought by community-based health insurance beneficiary affected the wellbeing of the people in Rwanda as revealed by the contribution of health policy toward maternal mortality alleviation. The study also shows that the role played by community based health insurance toward community wellbeing and maternal death alleviation were measured by taking into consideration hospital deliveries, easy access to medication, quality health services, financial risk protection, and nutritional awareness due to efforts and emphasis from health policy implementation.

According to one maternity ward attendee, community-based health insurance enhances improvement of livelihood of common people because of financial risk protection provided by CBHI whereby the money that has to be spent on buying medication in case of sickness now can be used to buy basic needs such food, shelter, clothing or properties such land, furniture and hence wellbeing and maternal mortality alleviation. This shows that health policy play a key role in maternal mortality through use of community based health insurance of common people health service seekers in Rwamagana Hospital.

Table 5.3: Descriptive statistics showing the views of respondents on how CBHI impacts maternal mortality in Rwanda, specifically in Rwamagana District Hospital

\begin{tabular}{lll}
\hline Respondents' perceptions & Frequency & Percentages \\
\hline Agree & 83 & 90.2 \\
Neutral & 8 & 8.7 \\
Disagree & 1 & 1.1 \\
Total & 92 & 100.0 \\
\hline
\end{tabular}

Source: Primary Data, 2018

The findings of the study in table 5.3 reveal that the majority of respondents have agreed that community based health insurance has positive impacts on maternal mortality whereby $83(90.2 \%)$ agreed, $8(8.7 \%)$ remained neutral and $1(1.1 \%)$ disagreed. These results show that health policy through its emphasis on community based health insurance has positive impacted on the lives of Rwamagama hospital attendees through the alleviation of maternal mortality.

\subsection{Impact of Training Medical Personnel and Maternal Mortality}

In this section, the researcher presented, analyzed and interpreted the respondents' views in relation to the influence of training medical personnel on maternal mortality rate in Rwamagana District Hospital.

Table 5.4: Descriptive statistics showing number of medical workers who did professional training

\begin{tabular}{lll}
\hline \multicolumn{1}{l}{ Respondents' perceptions } & Frequency & Percentage \\
\cline { 3 - 3 } Yes & 60 & 65.2 \\
No & 32 & 34.8 \\
Total & 92 & 100.0 \\
\hline
\end{tabular}

Source: Primary Data, 2018

The findings of Table 5.4 show that all medical personnel respondents have done professional training at $60(65.2 \%)$ whereas maternity ward attendees have not done professional courses at $32(34.8 \%)$. The findings reveal that medical personnel have done professional training at $100 \%$ which enhances the influence of training medical personnel against maternal mortality.

Table 5.6: Descriptive statistics showing perceptions on whether done professional training in midwifery

\begin{tabular}{llll}
\cline { 2 - 3 } Nespondents' perceptions & & Frequency & Percentages \\
One & 49 & 53.3 \\
Two & 23 & 25.0 \\
Three \& above & 14 & 15.2 \\
Total & 6 & 6.5 \\
\hline \hline
\end{tabular}

Source: Primary Data, 2018

The findings in Table 5.6 reveal that $49(53.3 \%)$ respondents did not do any professional training in midwifery, 23 (25.0\%) respondents have done only 1 training in midwifery, $14(15.2 \%)$ respondents have done two professional training in midwifery and $6(6.5 \%)$ respondents have done three and more courses in midwifery. The results proves that among the 49 respondents includes the 32 respondents of maternity ward attendees meaning that the number of medical personnel 
respondents who have done no training in midwifery is only 17 (18.5\%) means that medical personnel respondents have done training in midwifery at $81.5 \%$ and hence alleviating of maternal mortality.

Table 5.7: Descriptive statistics showing perception on whether medical personnel in midwifery and other professional courses can positively impact the rate of maternal mortality

\begin{tabular}{llll}
\hline Respondents' perceptions & & Frequency & Percentages \\
\cline { 2 - 3 } Agree & 86 & 93.5 \\
Neutral & 4 & 4.3 \\
Disagree & 2 & 2.2 \\
Total & 92 & 100.0 \\
\hline
\end{tabular}

Source: Primary Data, 2018

The findings of table 5.7 proved that $86(93.5 \%)$ agreed that training medical personnel in midwifery impacts maternal mortality, $4(4.3 \%)$ remained neutral about the perceptions when $2(2.2 \%)$ disagreed that training medical personnel in midwifery impacts maternal mortality. These results show that training medical personnel especially in midwifery alleviates the rate of maternal mortality.

\subsubsection{Impact of Mass Immunization and Maternal Mortality}

The results presented in this subsection show the impact of mass immunization on maternal mortality in Rwamagana Hospital, Rwanda.

Table 5.8: statement regarding impact of mass immunization and maternal mortality

\begin{tabular}{lllll}
\hline Statement & Agree & Neutral & Disagree \\
\hline $\begin{array}{l}\text { Immunization process is typically } \\
\text { administration of vaccine }\end{array}$ & $71(77.2 \%)$ & $20(21.7 \%)$ & $1(1.1 \%)$ \\
$\begin{array}{l}\text { The expectant mother has be immunized } \\
\text { Immunization has impacted maternal mortality } \\
\text { and poverty }\end{array}$ & $62(67.4)$ & $21(22.8 \%)$ & $9(9.8 \%)$ \\
\end{tabular}

Source: Primary Data, 2018

The findings in Table 5.8 proves that $71(77.2 \%)$ agreed that immunization process is a typically administration of vaccine, $86(93.5 \%)$ admits that an expectant mother has to be immunized, $62(67.4 \%)$ agreed on assumption that there is an impact of mass immunization on maternal mortal in terms of offsetting the effects of poverty by reducing the time and resources spent on nursing sick children or maternal deaths. Hence, this implies that immunization has a significant impact on reducing maternal mortality rate in Rwamagana Hospital, Rwanda.

\subsection{Correlation between health policy and maternal moritality}

The researcher correlated health policy and maternal mortality measures to find the relationship between the two by involving their measures such as community health-based insurance, mass immunization, training medical personnel, malnutrition, diseases, poverty, and poor antennal care. But before doing that the researcher looked at the perceptions of respondents about health policy and maternal mortality.

Table 5.9: Descriptive statistics on the Effects of Health Policy

\begin{tabular}{llll}
\hline Effects of health policy & Agree & Neutral & Disagree \\
\hline Community based health insurance & $83(90.2 \%)$ & $3(3.3 \%)$ & $6(6.5 \%)$ \\
Mass immunization & $68(73.9 \%)$ & $9(9.8 \%)$ & $15(16.3 \%)$ \\
Training medical personnel & $86(93.5 \%)$ & $1(1.1 \%)$ & $5(5.4 \%)$ \\
Building health facilities & $61(66.3 \%)$ & $8(8.7 \%)$ & $23(25.0 \%)$ \\
Provision of Medicare & $71(77.2 \%)$ & $9(9.8 \%)$ & $12(13.0 \%)$ \\
Educating women about reproduction & $62(67.4 \%)$ & $12(13.0 \%)$ & $18(19.6 \%)$ \\
Hygiene and sanitation & $56(60.9 \%)$ & $12(13.0 \%)$ & $24(26.1 \%)$ \\
\hline
\end{tabular}

\section{Source: Primary Data, 2018}

Findings in Table 5.9 are all about the effects of health policy towards maternal mortality reduction as revealed by respondents during data collection where they showed the contribution of this policy towards wellbeing. This policy has got seven constructs to deal with; whereby respondents agreed that training medical personnel brought positive effects to reduction of maternal mortality at the rate of $86(93.5 \%)$, only $5(5.4 \%)$ disagreed while $1(1.1 \%)$ was neutral about this idea, community based health insurance was agreed at $83(90.2 \%)$, disagreed at $6(6.5 \%)$ and neutral at $3(3.3 \%)$, followed by provision of Medicare, mass immunization, education women about reproduction, building health facilities and hygiene and sanitation at $71(77.2 \%), 68(73.9 \%), 62(67.4 \%), 61(66.3 \%), 56(60.9 \%)$ respectively. These results show that health 
policy has tackled all angles of health sector in relation to reduce maternal mortality because disagreements are reported to be at very minimal rate.

Table 5.10: Summary of the number of expectant mothers received Year 2014 - 2017 at Rwamagana Hospital

\begin{tabular}{llllll}
\hline Year & $\begin{array}{l}\text { Expectant } \\
\text { mothers }\end{array}$ & $\begin{array}{l}\text { Mother experienced } \\
\text { complication }\end{array}$ & $\begin{array}{l}\text { Maternal } \\
\text { deaths }\end{array}$ & $\begin{array}{l}\text { Maternal } \\
\text { mortality } \\
\text { rates }\end{array}$ \\
\hline 2014 & 243 & 4 & 1 & 0.0037 \\
2015 & 386 & 7 & 3 & 0.0075 \\
2016 & 494 & 2 & 0 & 0.0000 \\
2017 & 562 & 1 & 0 & 0.0000 \\
Mean & 315 & 3 & 1 & 0.0028 \\
\hline
\end{tabular}

Source: Hospital report, 2018

The findings in Table 5.10 shows that in 2014, average expectant mother was 243 with mortality reate of 0.0037 . In 2015 the numbers of expectant mothers were 386 with maternal mortality rate of 0.0075 , in 2016 the numbers of expectant mothers were 494 with maternal mortality rate of .000 while in 2017 , the numbers of expectant mothers were 562 with maternal mortality of .000 , and the average of 2014-2017 was 315 expectant mothers with maternal mortality rate of 0.0028 . These findings indicated that the number of maternal mortality rate reduced as the year increases expect of the year 2015, this proved that the health policy has a good impact on maternal mortality because every year comes with new strategies to counter-maternal mortality.

Table 5.11: Showing descriptive statistics about the views on causes of maternal mortality

\begin{tabular}{llll}
\hline Causes of maternal mortality & Agree & Neutral & Disagree \\
\hline Malnutrition & $88(95.6 \%)$ & $3(3.3 \%)$ & $1(1.1 \%)$ \\
Diseases & $72(78.3 \%)$ & $14(15.2 \%)$ & $6(6.5 \%)$ \\
Poverty & $58(63.0 \%)$ & $22(23.9 \%)$ & $12(13.0 \%)$ \\
Poor health services & $66(71.7 \%)$ & $11(12.0 \%)$ & $15(16.3 \%)$ \\
Poor antenatal care & $74(80.4 \%)$ & $13(14.1 \%)$ & $5(5.4 \%)$ \\
Lack of women awareness on motherhood & $69(75.0 \%)$ & $22(23.9 \%)$ & $1(1.1 \%)$ \\
Poor health facilities & $76(82.6 \%)$ & $12(13.0 \%)$ & $4(4.3 \%)$ \\
Inappropriate Medicare & $52(56.5 \%)$ & $23(25.0 \%)$ & $17(18.5 \%)$ \\
Inadequate immunization & $61(66.3 \%)$ & $16(18.2 \%)$ & $15(66.2 \%)$ \\
Untrained medical personnel in midwifery & $86(93.5 \%)$ & $2(2.2 \%)$ & $4(4.3 \%)$ \\
Home deliveries due to lack of mutuelle de sante & $82(89.1 \%)$ & $3(3.3 \%)$ & $7(7.6 \%)$ \\
Poor hygiene and sanitation & $56(60.9 \%)$ & $21(21.7 \%)$ & $16(17.3 \%)$ \\
\hline
\end{tabular}

\section{Source: Primary Data, 2018}

The findings in table 4.21 illustrates malnutrition as the highest rank which causes maternal mortality with 88 (95.6\%) agreed, 1 (1.1\%) disagreed, and 3 (3.3) stayed neutral, followed by untrained medical personnel in midwifery, home deliveries due to lack of mutuelle de sante (especially community based health insurance),poor health facilities, poor antenatal care, diseases, lack of women awareness on motherhood and reproduction, poor health services, inadequate immunization, poor hygiene and sanitation and inappropriate Medicare with ranks of $86(93.5 \%), 82(89.1 \%), 76(82.6 \%), 74$ (80.4\%), 72 (78.2\%), 69 (75.0), 66 (71.7\%), 61 (66.3\%), 58 (63.0\%), 56(60.9\%), $52(56.7 \%)$ respectively. Therefore, the highest level of disagreement was on inappropriate Medicare at $17(18.5 \%)$ while the lowest was on malnutrition and lack of women's awareness on motherhood and reproduction at 1 (1.1\%). The highest rank of neutrality was on inappropriate Medicare at $23(25.0 \%)$ while the lowest was on untrained medical personnel in midwifery at $2(2.2 \%)$. The results show that health policy has to tackle many health related issues in order to ensure the alleviation of maternal mortality. 
Table 5.12: correlation Analysis between health policy and maternal mortality

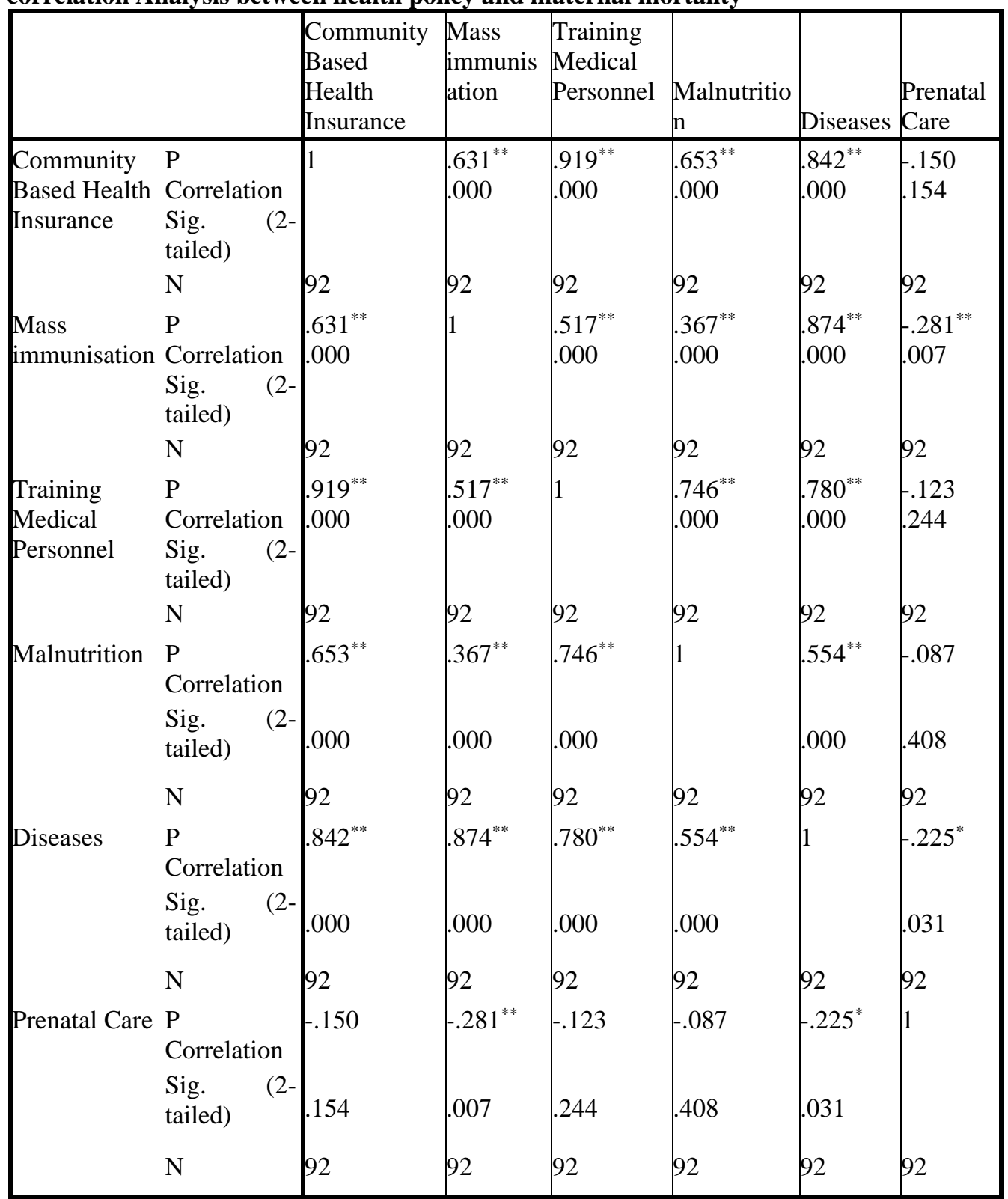

**. Correlation is significant at the 0.01 level (2-tailed).

*. Correlation is significant at the 0.05 level (2-tailed).

Source: Primary Data, 2018

The findings in Table 5.12 revealed that there is relationship between health policy and maternal mortality whereby community health insurance has a positive significant correlation with mass immunization which has p-value of .000 which less than 0.01 level with Pearson correlation of 0.631 ,training medical personnel with Pearson correlation of 0.517 , building health facilities malnutrition with Pearson correlation of 0.780 , and diseases with Pearson correlation of 0.554 which indicate the positive significant correlation. However, all the measures of health policy and maternal mortality gave a negative correlation with poor antennal care.

\section{Conclusion and Recommendations}

The research was carried out to assess the impact of health policy on maternal mortality in Rwanda - Rwamagana district hospital, the collected data and information indicates that health policy has much impacted maternal mortality in all health sectors of Rwamagana Hospital through common people owning community based health insurance, easy access to medication, financial risk protection through protecting the resources spent on nursing sick children and maternal deaths, building of medical infrastructures and facilities, nutritional advices to mention but few. This research also indicated that health policy have impacted Rwamagana District Hospital in alleviating maternal mortality because it played a huge role in the improvement of health services, antenatal care, hygiene and sanitation, reducing poverty through financial risk protection made by mutuelle de santé (Mutual health Insurance), educating women about motherhood and reproduction through sociologists, and Abajyanama b' ubuzima (Health Advisors), focus on mass immunization, and training medical personnel in midwifery all in all to enhance health policy to positively impact and alleviate maternal mortality in Rwamagana Hospital. 
Basing on the findings of the study and constraints accounted, the researcher would like to recommend influencing the significant impact of health policy on maternal mortality. The implementation and formulation of policies should involve local people more especially in design and identification of the problems and needs to alleviate the health related problem because a big number of local people has asserted that they faced challenges concerning health related policies at the first phase of implementation stage only because many of these policies are top down formulated policies where the local people or direct beneficiaries don't have a say in the formulation of these policies and then challenge them at implementation stages where the local leaders have to come to take their properties especially livestock for the exchange of understanding the policy and implement it though the local people have later recognize that these policies are for their betterment and wellbeing. Other challenges are less numbers of medical personnel compared to hospital attendees of Rwamagana Hospital, lack of strong medication where people are required to buy their in private pharmacies, less numbers of maternity ward though the hospital is being reconstructed, spending time on paying health dues on insurance flap compare to the time to be spent with doctor, less number of ambulances in case of transporting a complicated mother, and poor feeding roads to mention but few

Medical personnel should ensure full attention while providing medical services especially in case of delivery because when the medical personnel is not caring about the service that is providing make the country lose two lives of one, and remember those are the hands that have to develop our country. The ministry of health has sorted it by endorsing that no medical personnel has to pick a phone call while on work, this has saved the lives of many but there still a needy to teach them how customer care is given though they are in government owned hospital. All in all to ensure that health policy helps us to alleviate maternal mortality. The researcher also recommend that local leaders should be part and partial of explain the new formulated health policies or any other policy or law concerning the local people rather than waiting the time of implementation, so that the local people should not face charges or ignorance of policies especially health related policies and anti - maternal mortality relate measures to ensure a society free of maternal mortality.

\section{References}

[1].Amin, M.E. (2005) Social Science Research: Conception, Methodology and Analysis. Makerere University Press, Kampala.

[2].Brugiavini, A., \& Pace, N. (2016). Extending health insurance in Ghana: Effects of the National Health Insurance Scheme on maternity care. Health Economics Review, 6(1), 7-13. doi:10.1186/s13561-016-0083-9

[3].Carrin G, Doetinchem O, Kirigia J, (2008). Social health insurance: how feasible is its expansion in the African Region. Dev Issues, 10(2):7-9

[4].Gay, L. R. (1987) Educational Research: Competencies for Analysis and Application. 3rd.edn. London: Merrill Publishing.

[5].Laurell (2013) Granting Universal Access to Health Care, Mexico City.

[6].Lewis G, Drise J, Botting B, et al. (2001). Why mothers die: Report on Confidential Enquiries into Maternal Deaths in the United Kingdom, 1997-1999, Department of Health on behalf of the controller of Her majesty's Stationery Office, London.

[7].Miles, B, M \& Huberman, M. (1994). Qualitative Data Analysis: A Methods Sourcebook. Arizona State University, USA.

[8].Ministry of Health, (2014). Key Health Indicators: Maternal and child health program. Kigali Rwanda.

[9].Ministry of Health, (2018). Rwanda MOH National Family planning and adolescent sexual and reproductive health (FP/ASRH) strategies. Kigali, Rwanda.

[10]. Mugeni C, Ngabo F and James H, (2011). Community Performanced-Based Financing in Health: Incentivizing Mothers and Community Health Workers to Improve Maternal Health Outcomes in Rwanda, Kigali, Rwanda: Ministry of Health.

[11]. Owoo, N.S \& Lambon-Quayefio, P. (2013). National health insurance, social influence and antenatal care use in Ghana Health Economics Review, 3 (19), 13-20

[12]. Paf et al,. (2016). Beyond the numbers of maternal near-miss in Rwanda - a qualitative study on women's perspectives on access and experiences of care in early and late stage of pregnancy.

[13]. Rwanda EPCMD, (2017). Rwanda EPCMD country summary: Selected Demographic and Health indicator for Rwanda. Kigali. Rwanda.

[14]. Sekabaraga, Diop, Soucat (2011) Can innovative health financing policies increase access to MDG-related services? Evidence from Rwanda. Health Policy and Planning. Kigali, Rwanda.

[15]. WHO (2005) Sustainable health financing, universal coverage and social health insurance.

[16]. World Health Assembly Resolution 58.33. Geneva: World Health Organization.

[17]. WHO (2016) World Health Statistics: Monitoring Health for the SDGs. Geneva: World Health Organization.

[18]. Yamane, Taro. (1967). Statistics, An Introductory Analysis, 2nd Ed., New York: Harper and Row. 